\title{
Desenvolvimento organizacional em parceria no setor social: Dor, dança e drama
}

\author{
Ivo Manuel Pontes Domigues*
}

\section{O problema teórico e metodologia da pesquisa}

ste estudo procura resposta para este problema de investigação: como organizações em parceria gerem a sua participação coletiva para obterem benefícios privados? Esta análise assume forma mais descritiva, procurando captar a diversidade e complexidade de fatores reconhecidamente existentes nas organizações e nas atividades organizadas. Depois de produzida uma descrição do processo de partilha, procuro encontrar princípios organizadores da conduta coletiva em órgãos adhocráticos, constituídos para resolver problemas ou realizar projetos específicos e que se extinguem após a conclusão da sua missão.

O contexto da pesquisa é a atuação de uma Parceria de Desenvolvimento (PD), composta por seis organizações da economia social, pelo gabinete de ação social da Câmara Municipal (Prefeitura) e uma empresa de consultoria. Foi constituída para melhorar o Sistema de Gestão da Qualidade (SGQ) das organizações da economia social e obter a sua certificação pelo referencial normativo ISO 9001:2000. Estas organizações são Instituições Privadas de Solidariedade Social (IPSS), organizações não-governamentais financiadas pelo governo para prestar serviços sociais às comunidades onde atuam. As IPSS participantes operam num mesmo município, com população ativa predominantemente aplicada ao sector secundário. No seu conjunto,

Professor do Instituto de Ciências Sociais, Dept. de Sociologia. Universidade do Minho, Campus do Gualtar, Braga, Portugal. Endereço eletrônico: ivodomingues58@gmail.com 
os serviços prestados incluem serviços de apoio domiciliário, centro de dia e residência para idosos, centro de trabalhos continuados para idosos em fim de vida, centro de acolhimento de pessoas portadoras de deficiência física e/ou intelectual, creche, jardim infantil e centro de atividades em tempos livres para crianças.

A pesquisa toma como unidades de observação os comportamentos dos membros da PD que exercem funções de gestão e de direção nas IPSS e que as representam nos órgãos de decisão da PD. Trata-se de comportamentos de decisão coletiva sobre a construção dos SGQ e dos Recursos Técnico-Pedagógicos (RTP), recursos normativos e instrumentais que organizam e regulam a gestão estratégica e operacional da qualidade. A coleta de dados foi realizada por observação participante nas reuniões dos órgãos que governam a PD nos domínios estratégico e operacional, respectivamente compostos por dirigentes e por gestores, durante dois anos, período de existência do projeto. Ao todo, foram observadas 28 reuniões, totalizando cerca de 120 horas.

Para encorajar a cooperação é necessário satisfazer diferentes requisitos: afastar as sombras do futuro, a partir do aumento da frequiência e da duração das interações; mudar a perspectiva de ganho, tornando os incentivos pela cooperação a longo prazo mais elevados do que os incentivos pela defecção a curto prazo; ensinar as pessoas a tomar conta umas das outras, incentivando o altruísmo; ensinar a reciprocidade e a equidade para permitir a recompensa da mútua cooperação; melhorar as capacidades de reconhecimento, lembrando os cooperantes noutras interações passadas e lembrar as mais importantes características dessas interações (AXELROAD, 1984, p.124-41). Neste estudo veremos como os responsáveis das organizações parceiras desenvolvem diversas formas de relacionamento, alinham em interações de intensidade variável, monitorizam a conduta segundo intencionalidades mutáveis e usam a memória coletiva de modo seletivo.

\section{Configuração da cooperação}

Os objetivos da PD eram os seguintes: 1) testar um método de certificação de SGQ em parceria tomando como referencial 
a Norma ISO 9001:2000; 2) certificar pelo menos uma valência em cada organização desenvolver um modelo partilhado de certificação dos seus SGQ; 3) difundir a inovação bem sucedida pelas restantes organizações do setor social que operam no conselho. Havia outro objetivo, nunca oficialmente assumido, mas frequientemente reconhecido nos encontros de trabalho: financiar as atividades correntes das IPSS.

O projeto foi financiado pelo "Programa Europeu Equal", destinado a promover medidas de prevenção e combate ao desemprego, desenvolvimento de recursos humanos e promoção da igualdade de oportunidades no acesso ao mercado de trabalho. A constituição daquela PD foi facilitada pela prévia existência da rede social, organizada em torno da câmara municipal (prefeitura) e que agrega as IPSS do conselho e outras instituições dedicadas à atividade social. Dentro da rede social haviam-se constituído grupos para desenvolver áreas de interesse comum e um dos grupos abarcara o desenvolvimento organizacional, tendo sido dentro deste que se constituiu a PD. A realização do projeto estendeu-se ao longo de dois anos.

As organizações envolvidas na PD e os seus representantes envolvidos em diversos encontros, de natureza diretiva e operacional, constituem uma configuração. Esta consiste em padrão de comportamento sustentável desenvolvido em fluxo pelos jogos dos participantes unidos por rede de interdependência (ELIAS, sd, p.142). Para compreender a atuação dos membros da PD, é necessário caracterizar a configuração, identificando as bases de poder dos seus membros, vistos como jogadores; os padrões de atuação que eles desenvolvem, vistos como arranjos provisórios de atuação; e as mudanças ocorridas, vistas como reflexo da plasticidade da conduta dos participantes, propiciadoras de diferenciação e de integração.

Esta configuração assenta nos seguintes pressupostos organizacionais: a participação inicial foi voluntária, consagrada em candidatura a programa de financiamento público; a integração de parceria é condição para obter o desejado financiamento; todas as entidades possuem igual estatuto; a PD possui sistema formal de gestão que define competências e responsabilidades entre as orga- 
nizações parceiras; a coordenação foi confiada a uma das organizações; todas as organizações possuem responsabilidades de execução de atividades na parceria; a parceria tem existência limitada, restrita a execução do projeto. O projeto é sujeito a avaliação externa por entidade independente e paga pelo Estado.

As organizações controlam fatores necessários ao sucesso da PD o que reforça a recíproca e coletiva dependência. A empresa privada possui competências em gestão da qualidade e em gestão de recursos humanos. A câmara municipal possui capacidade de mobilização das IPSS do conselho e goza do prestígio de ser importante entidade de gestão territorial. As IPSS detêm conhecimentos e competências para atuar na prestação dos serviços sociais. Cada tipo de organização controla recursos distintos, residindo a importância da sua participação no valor pelos parceiros reconhecido ou atribuído a esses fatores para o sucesso do projeto e à capacidade para controlá-los e manter restrito o seu uso. Neste caso, os mais importantes recursos são controlados pela empresa consultora, que sabe interpretar a adaptar a Norma ISO tomada como referencial para montar os SGQ, e pelas IPSS, que conhecem a legislação do setor e sabem como prestar os serviços protocolados com o Estado. Os recursos controlados pela câmara municipal são mais necessários na fase final da realização do projeto, no momento da disseminação dos modelos de gestão criados na PD pelas outras organizações do setor social.

Todas as organizações tinham de assumir responsabilidade formal e operacional pela execução das atividades que a PD necessariamente teria de executar. A empresa de consultoria ficou com a responsabilidade pela execução dos RTP, a câmara municipal ficou com a responsabilidade pela comunicação externa da PD, uma IPSS ficou com a responsabilidade pela execução do balanço de competências, outra ficou com a responsabilidade pela gestão financeira e coordenação operacional da PD, outra com a cooperação internacional com PD que desenvolviam outros projetos na área social, outra com a responsabilidade de elaboração de um manual de boas práticas do setor social, outra com a coordenação da formação interna na PD e outra ficou sem nenhuma responsabilidade de realizar atividade para a PD. 


\section{A cooperação como dor, drama e dança}

Para construir sentido sobre a realidade observada adotei uma alegoria constituída por três metáforas: dor, drama e dança. Elas permitem captar diferentes aspectos e materializações da realidade e propor compreensão mais global da cooperação inter-institucional. Concretamente, quando usadas de modo articulado, facilitam perceber expressões diversas da realidade: o desenvolvimento de sentimentos amargurados que a interação e a inovação normalmente permitem ou estimulam e o modo como eles regulam a relação interativa e inovadora; os papéis desempenhados na sustentação de versões convenientes da realidade e como os papéis desempenhados reproduzem a realidade representada de cooperação e inovação; evolução das sequiências de ações realizadas em movimentos e como os movimentos realizados implicam a coreografia da atuação. Em suma, esta alegoria permite ver a realidade como efeito da relação interdependente dos agentes, como efeito coreográfico dos movimentos dos dançantes, como efeito dramático dos atores e como efeito amargurado das interações.

A metáfora do teatro foi extensamente conceitualizada e usada por Goffman (1983). A metáfora da dança e a metáfora da dor, até onde o meu conhecimento alcança, têm sido usadas de modo reificado e parcamente conceitualizado. As metáforas estimulam mais o pensamento do que a simples linguagem, pois permitem estabelecer correspondências ontológicas apoiadas em padrões de inferências (LAKOFF, 1996, p.205). A análise metafórica permite estabelecer correspondências entre o domínio da experiência (dança e dor) e o domínio de análise (gestão da participação). Por isso, formulo a relação entre estes dois domínios a partir das expressões "a cooperação é teatralizada”, "a cooperação é movimento" e a "cooperação é dolorosa".

Quando ouvimos expressões como "andamos todos a fazer de conta" e "não basta ser honesto, também é preciso parecer", "ando numa roda viva" e "vou acertar o passo" ou "crescer, custa" e "quem não se sente, não é filho de boa gente" são expressões do âmbito, respectivamente, do drama, da dança e da dor. O mapeamento dessas metáforas permite encontrar diversas correspondências entre a realidade empírica analisada e as metáforas convocadas para 
analisar: participação, dramatização, coreografização e dolorização; representantes das organizações, atores, dançarinos e sofredores; instrumentos administrativos, instrumentos expressivos, instrumentos cinéticos e sentimentos.

O desenvolvimento do projeto pela PD implicou evolução das configurações concertadas entre diferentes pessoas. Para compreender a evolução configuracional proponho adotar as metáforas da dor, do drama e da dança e, a partir delas, construir sentido sobre a atuação dos parceiros. Esses sentidos são apresentados na forma de proposições de termos recíprocos proporcionais. Opto por esta forma porque nos parece que ela revela mais adequadamente os atributos da realidade - dinâmica relacional, reciprocidade dialética e movimento contínuo - ao mesmo tempo em que permite captar relações estruturadas e estruturantes entre adereços - movimentos - dançantes - expectantes. Estas formulações exprimem princípios estruturais, "conjuntos de interconexões” institucionalizadas que governam a reprodução dos sistemas sociais, constituídos pelas práticas sociais recíprocas e recursivas dos agentes (GIDDENS, 1979, p.141). Para formular princípios organizadores da conduta adoto como critérios dimensões da estruturação social, concretamente a significação, permitida pela comunicação e pelo uso de esquemas interpretativos partilhados, a legitimação, assente na moralidade e nas regras morais, e a dominação, facilitada pelo uso de recursos de poder (GIDDENS, 1988, p.122). A formulação destes princípios permite generalização por indução analítica (DENZIN, 1989, p.165-75) à gestão desta PD. A generalização destes princípios a outros casos não é legítima e apenas podem ser adotados como hipóteses de pesquisa.

\section{Dolorização na parceria}

\subsection{A interação amargurada}

\subsubsection{Substituição de responsabilidades sem dor}

Uma das IPSS ficou responsável pela realização do Balanço de Competências, atividade exigida pela entidade financiadora. A organização não detinha competências instaladas para realizar 
aquele processo e a técnica que contratou para assessorar o projeto também não era detentora dessa capacidade. O primeiro relatório apresentado era sofrível e todos os membros da equipa de gestores que o apreciaram alinharam na crítica aberta e extensa. A atividade acabou por ser realizada com reconhecido mérito porque nela envolveu-se arduamente um dos técnicos da empresa consultora. Para além do instrumento de medição que já antes elaborara, definiu metodologia de construção dos resultados e ele mesmo encarregou-se de elaborar o relatório, o qual mereceu reconhecida apreciação de técnicos. A atividade realizada pela PD acabou por merecer honrosa referência da direção nacional do Programa Equal. Aquela substituição imprevista, mas necessária de competências não motivou, na altura, expressão de amargura por parte do responsável da empresa nem de nenhum dos seus técnicos.

\subsubsection{Negociação do financiamento e desilusão}

Já na parte final da execução do projeto, quando se analisou a utilização a dar a verbas excedentes de algumas rubricas, o líder da organização parceira responsável pelo balanço de competências reclamou para si mais dinheiro porque a sua atividade era a menos bem orçada e o balanço de competências tinha exigido muito da sua técnica. Por sua vez, o responsável da empresa de consultoria reclamou para si idêntico direito porque se vira obrigado a realizar atividades que não estavam previstas e porque sempre considerara e dissera que havia atividades que estavam sobreorçamentadas, como era a da coordenação da PD. Aquelas verbas acabaram, por decisão majoritária da PD, a serem destinadas ao pagamento do serviço de certificação, atividade não prevista financiar, mas que a direção do Programa Equal aceitou suportar. O pedido de reforço do financiamento desejado pelas duas organizações parceiras teve de ser diretamente solicitado à direção do programa, que o não concedeu.

A amargura foi aqui sentida pelos responsáveis daquela IPSS, que não viam pelos líderes das organizações parceiras reconhecida o seu envolvimento no sucesso da PD, revelado na realização de uma atividade que ninguém desejara, por ser tecnicamente complexa, e na disponibilidade das instalações para todas as reu- 


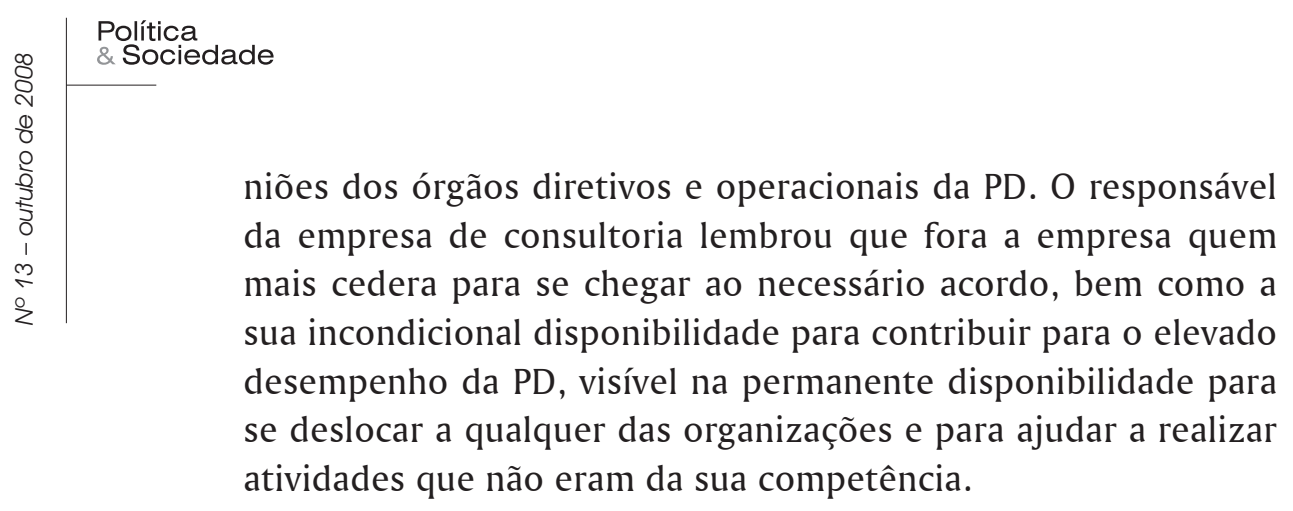

\subsubsection{Disseminação dos produtos e confrontação}

A última fase do projeto correspondia à divulgação dos RTP desenvolvidos pela PD e aprovados pela direção do Programa Equal. Esta fase seria realizada por meio de candidatura específica a apresentar ao programa. A organização que coordena a PD queria que a nova candidatura envolvesse apenas a ela e a empresa de consultoria, autora dos RTP. Esta opção causou profundo desagrado entre os responsáveis de algumas das organizações. Duas delas não queriam participar porque já haviam atingido os objetivos que almejavam - a certificação do seu SGQ. Três delas reivindicaram inclusão na candidatura, alegando que eram co-responsáveis pelo desenvolvimento dos RTP e que também tinham interesse em participar na sua divulgação.

Este marcado interesse não visava benefícios financeiros porque estes eram diminutos, pois, nesta fase, apenas podiam afetar algum tempo de um técnico superior ao projeto. A sua reivindicação visava permitir que as organizações melhorassem a sua visibilidade regional junto de entidades públicas e junto doutras organizações do setor. Nesta fase, as demais organizações do setor instaladas no conselho seriam convidadas a adotarem os RTP e a melhorar o seu desempenho na qualidade e as organizações da PD seriam apresentadas como modelos de atuação na gestão da qualidade e dos recursos humanos. O que os responsáveis daquelas organizações sentiram foi a monopolização dessa oportunidade por uma das organizações parceiras que, desse modo, para si reservava essa prestigiosa função. Os responsáveis das demais organizações avaliaram muito mal esta pretensão e, quer em reunião quer em conversas informais, muito negativamente a comentaram. 


\subsection{Princípios da dolorização}

A atuação dos responsáveis das organizações parceiras em diversas circunstâncias provocou dor. Esta pode ser partilhada segundo diversos tipos de comunicação: verbal ou não verbal, consciente ou subconsciente, aberta ou dissimulada, simples ou complexa, literal ou figurativa, intelectual ou emocional (HUNTER, 1996, p.35). A expressão da dor é regulada, pois existem regras sociais para adequar a sua comunicação às situações de atuação (GOLEMAN, 1996, p.113). A dor é experiência sensorial e emocional desagradável associada a ameaça presente ou futura (KANNER, 1997, p.1), mediada por fatores cognitivos influenciados por contextos sociais e culturais e condicionada pelas expectativas do grupo normativo de pertença (PAYNE \& HORN, 1997, p.83). A dor nasce da interação social e condiciona a interação social, é efeito inesperado das atividades de cooperação para a inovação e pode reduzir a cooperação e comprometer o alcance da inovação. Na gestão de projetos em parceria, a conduta dolorida parece seguir princípios anímicos, formas de combinar estados de alma e expressões de sentimentos.

A amargura é tanto maior quanto menor é a legitimidade das formas de partilha adoptadas.

As parcerias são criadas para aproveitar oportunidades ou resistir a constrangimentos de modo a atrair mais recursos e a desenvolver as organizações ou a proteger os recursos existentes e a garantir mais possibilidades de sobrevivência das organizações parceiras. A parceria tem, assim, na sua gênese uma vocação racionalista e pragmática, mesmo quando a sua missão reveste-se de finalidades filantrópicas. De modo geral, é mais fácil obter consenso quanto à partilha dos fins do que quanto à partilha dos meios e até é frequiente transformar os meios em fins, alteração que pode existir desde o início e ser sabiamente ocultada ou ser desenvolvida ao longo do processo. Esta questão da partilha dos meios torna-se mais aguda quando há escassez de recursos, mas também pode ocorrer quando há excesso de recursos. Quando isso acontece, a preservação dos fins da parceria de todos exige mais intenso cuidado e diálogo na procura de soluções concertadas. Neste processo de negociação de definições da realidade, a construção e sentidos e a argumentação 
assumem enorme importância, dificilmente realizável em reuniões agendadas e em encontros formais. A procura de soluções e consensos exige negociação intimista em encontros informais. Todas as soluções precisam aparecer, aos olhos dos parceiros, como justas ou, pelo menos, como toleradamente injustas. E a legitimidade dos modos de partilha e uso dos meios frequientemente constrói-se por meios formalmente ilegítimos, mas pragmaticamente úteis.

A amargura é tanto maior quanto menor é a significação de sinais de comprometimento

Os parceiros não se limitam a participar, também investem muito na emissão de sinais de comprometimento nos fins da parceria. Realizar atividades extraordinárias e não previstas, dispensar outro de compromisso de realizar atividades difíceis para as quais não tem competências, procurar soluções novas para problemas não resolvidos, voluntariamente disponibilizar recursos para uso comum, acudir a parceiros sem equacionar os custos são exemplos frequientes de implicação no projeto coletivo da parceria. Estas generosas dádivas fazem parte de sistema de troca quase sempre desigual, mas que ninguém expressamente equaciona enquanto não surgem sinais de perda absoluta ou relativa de recursos. A generosidade raramente é, ou nunca é, genuinamente filantrópica, pois sempre os membros mais generosos esperam alguma forma de retribuição, na forma de uso, troca ou reconhecimento. Quando os membros mais generosos vêem que a generosidade dos seus atos não colhe esse significado ou quando descobrem que o significado da generosidade não merece consideração especial, reduzem ou suprimem a generosidade e podem passar a exigir compensação material para atos que eram originalmente mais ou menos voluntários. O desinteressado altruísmo pode, nestes casos, ser transformado em inesperado materialismo.

A amargura é tanto maior quanto maior o uso arbitrário do poder

As parcerias necessitam que os parceiros usem o poder, mas carecem de uso qualificado do poder, ou seja, que seja usado de forma consensualizada e concertada, de modo a respeitar e reproduzir a condição equalitária dos parceiros. O poder deve ser aplicado na resolução de problemas comuns ou na obtenção de vantagens coletivas, mas não para obter benefícios particulares ou 
privados. A aplicação não conforme do poder pode causar descontentamentos insanáveis, abrir fraturas incorrigíveis porque reduz as oportunidades de participar na tomada de decisão e enfraquece a posição dos membros desintegrados da decisão ou afastados dos seus benefícios. Nesta perspectiva, a tomada de decisão por maioria pode não ser mecanismo suficiente para manter o interesse dos diferentes parceiros nos fins da parceria e garantir o seu mais elevado empenho nos seus resultados. Da mesma forma, presumir a opinião dos outros parceiros em decisões que interferem com os seus interesses também não é aceite. Considera-se que cada organização deve decidir o grau de envolvimento que deseja manter, em pé de igualdade com todos os parceiros, não sendo tolerado que alguém por si decida com base na presunção dos seus interesses.

\section{Dramatização na parceria}

\subsection{A interação coreográfica}

\subsubsection{Representação da utilidade dos RTP e recepção condicionada}

Todos os RTP foram apresentados dentro do grupo temático da qualidade criado pelo Programa Equal. A apreciação dos instrumentos da qualidade apresentados recebia considerações de poucos dos participantes, na maior parte dos casos porque não se sentiam suficientemente competentes para arriscar opinião, preferindo desempenhar papel de atentos espectadores. Alguns dos comentadores faziam depender o sentido e intensidade da sua opinião da relação que queriam desenvolver com a organização que apresentava os RTP que havia concebido. Poucos eram aqueles que, de forma aceitavelmente objetiva e isenta, comentavam o trabalho dos parceiros. Em alguns casos, a interação adquiriu tensão conflituosa, como aconteceu quando eram produzidas apreciações mais críticas de alguns RTP apresentados, quase sempre pelo coordenador da consultoria da $\mathrm{PD}$, que não eram vistas como ataques pessoais ou apreciações discriminatórias pessoais porque eram, normalmente, bem sustentadas em conhecimentos da qualidade. 


\subsubsection{Representação da utilidade do projeto e aplauso}

Grande parte da energia disponível para a atuação do grupo foi investida na construção de imagem pública da PD. Esta representação da competência foi encenada em diversos palcos: no grupo da qualidade do Programa Equal, que integrava todos os projetos que tinham a qualidade como argumento de atuação e que apreciavam todos os RTP concebidos; nos encontros formais com a direção regional da segurança social, órgão regional do governo, de modo a seduzir este organismo para participar como observador no projeto; nos encontros com dirigentes e quadros doutras organizações, seminários em que se divulgavam os benefícios da gestão da qualidade e as vantagens do projeto. Como efeitos das sucessivas representações, a pessoa responsável pela coordenação do projeto foi convidada para coordenar o grupo temático do Programa Equal, a pessoa responsável pela coordenação da consultoria foi convidada para participar naquele grupo a título excepcional, e o projeto adquiriu notoriedade nacional entre os públicos do sector social. Os seminários realizados atraíram sempre muita gente, incluindo representantes de diversas organizações oficiais e dirigentes e gestores de muitas organizações do setor social.

\subsubsection{Representação da qualidade e certificação}

A norma da qualidade adotada como referencial prescreve os requisitos obrigatórios, mas não determina os modos de atuar, cabendo a cada organização materializar os requisitos em práticas concretas e definir os seus próprios objetivos da política da qualidade. Assim, as organizações parceiras puderam ver os seus SGQ certificados apesar de, em alguns aspectos, terem optado por ambições mínimas de Gestão da Qualidade. Por exemplo, evitaram adotar limites temporais para tratamento de reclamações, prevenindo constrangimentos de execução das tarefas previstas para este processo e permitindo que a resposta aos reclamantes atrase-se demasiado, não satisfazendo as necessidades e expectativas. Outro exemplo é fornecido pela escolha de indicadores dos objetivos da qualidade, em alguns casos pouco úteis para medir o desempenho da qualidade e noutros casos incongruentes com os objetivos que pretendem operacionalizar. 


\subsection{Princípios dramatúrgicos}

Os signos da realidade são manipulados para fornecer uma versão adequada e falseada da realidade, pois a representação de uma atividade difere da própria atividade e constitui sua falsa representação (GOFFMAN, 1983, p.59-67). A dominação dramática ocorre quando a representação usa o poder como meio de persuasão da platéia e não como meio de subordinação dos atores, sendo a atuação regulada por meio de sinais emitidos facilitadores de definições de situação (idem, p.221). Para isso, é necessário liderar a representação para garantir a dominância diretiva, propiciadora da distribuição de papéis e da fachada a eles associada e da correção de representações indesejadas, e a dominância dramática, propiciadora da representação de papéis de liderança desprovida de capacidades de direção (idem, p.93-98). O drama é interação social ocorrida nos palcos dos encontros quotidianos, entre atores e platéias, espacial e temporalmente presentes e que fazem da co-presença condição do sucesso dramático. O drama é argumento e significação, personagens reais ou imaginadas, regras e contra-regras, papéis concordantes e discrepantes, sinceridade e cinismo. Mas, na gestão de projetos em parceria, as representações parecem seguir princípios dramatúrgicos, modos de combinar os papéis sociais:

Quanto maior a legitimidade da Norma, maior o efeito dramatúrgico.

A Norma ISO adotada como referencial para a certificação oferece a principal fonte inspiradora do que orienta as representações de papéis. Ninguém discute a sua legitimidade, ninguém equaciona a sua utilidade, todos a recebem em credulidade e nos seus requisitos vêem atributos dos papéis organizacionais que é necessário adotarem e representarem para que os efeitos dramáticos sejam vantajosos e suficientemente convincentes. A dramatização bem sucedida dos papéis da qualidade é certificada pela atribuição do direito de usar signo distintivo que indicia as platéias estarem na presença de organização capaz de desempenhos superiores e, por isso, merecer a sua confiança e preferência. O reconhecimento público da dignidade da Norma, inspiradora e reguladora da Gestão da Qualidade, implica e amplia o reconhecimento da competência organizacional. 
Quanto mais cerimoniosa a platéia, mais eficaz a dominância dramática.

A apresentação pública do projeto e dos RTP que ele foi permitindo conceber foi sempre feita para platéias muito institucionalizadas, ou seja, composta por pessoas dotadas de funções representativas de organizações reguladoras do setor social e para diretores e gestores das organizações da parceria e de outras organizações convidadas. O argumento é técnico, mas a platéia é cerimoniosa. Nestas circunstâncias as pessoas que usam da palavra podem facilmente desempenhar o papel de legitimadores da mudança anunciada e desejada porque a platéia, por incapacidade, por decoro ou por conveniência, não levantará questões embaraçosas para quem representa ou promove a nova ordem da gestão.

Quanto maior a diferença de capacidades conceptuais, menor a significação técnica partilhada e maior a representação de papeis concordantes

A heterogeneidade cognitiva dos atores reduz as possibilidades de permuta de opiniões e de construção ativa das soluções técnicas corporizadas nos RTP, nos procedimentos da qualidade e nos manuais da qualidade. A incapacidade para ler os requisitos da Norma e para ajustá-los aos instrumentos da qualidade permite apresentar soluções incoerentes ou desajustadas, expondo-se às críticas mais fundamentadas dos membros mais competentes. $O$ efeito pode ser o aparecimento de indesejáveis sentimentos dolorosos e de inúteis papéis de participação mais concordante e ritualista.

\section{Coreografização na parceria}

\subsection{A interação coreográfica}

\subsubsection{Acusação e contra-acusação}

Na preparação da candidatura da PD, participaram apenas duas IPSS e a empresa de consultoria. Aos seus responsáveis coube a árdua atividade de conceber os objetivos, os meios, os RTP, o calendário e formalizar a candidatura. Para aproveitar e reforçar a candidatura, uma terceira organização foi convidada a participar, por decisão consensual dos parceiros que naquele momento montavam 
a candidatura. Quando os responsáveis das organizações que, no âmbito da rede social do conselho, integravam o conselho para o desenvolvimento organizacional souberam da candidatura promoveram reunião daquele órgão para reivindicarem a sua entrada. Esta reivindicação assentava no argumento de que aquelas três organizações haviam sido designadas para encontrarem financiamento para suportar o desenvolvimento do setor social no conselho e que estavam traindo essa confiança. Este argumento era negado pelos responsáveis das organizações que tinham arrancado com a candidatura, com base noutro argumento que imputava aos líderes das organizações reivindicantes contínuo desinteresse pela procura de soluções e que agora, de modo oportunista, desejavam embarcar em promissora candidatura em curso. Ainda havia outro argumento, discretamente enunciado, e que se prendia com a incompatibilidade de caráter de alguns responsáveis destas organizações. Aquele argumento não era aceito como válido pelo responsável da Câmara Municipal, mas esse via com bons olhos o desejado alargamento, pois nele via vantagens para a política social do conselho. Após diversas horas de discussão, em que a construção de sentido assumiu por vezes formas violentas, a solução foi deslocada para o responsável da empresa de consultoria na forma de questão sobre a possibilidade operacional de alargar o projeto a mais três organizações. Considerando a tensão observada e as fraturas que a decisão poderia deixar, acabou por emitir opinião favorável sobre a exequiibilidade do projeto alargado a seis organizações beneficiárias.

\subsubsection{Legitimação e silenciação}

Quando da decisão sobre o uso a dar a verbas excedentes de atividades que tiveram insuficiente desempenho, o responsável da empresa consultora esforçou-se em argumentar para reforçar o orçamento das atividades a si confiadas. Lembrou que, quando da negociação inicial do orçamento, foi a empresa quem mais cedeu para que fosse obtido acordo coletivo sobre o orçamento e que a coordenadora, na altura, havia afirmado que o valor então cedido poderia ser compensado, pois no final a empresa poderia solicitar mais financiamento. Um responsável de uma das organizações 


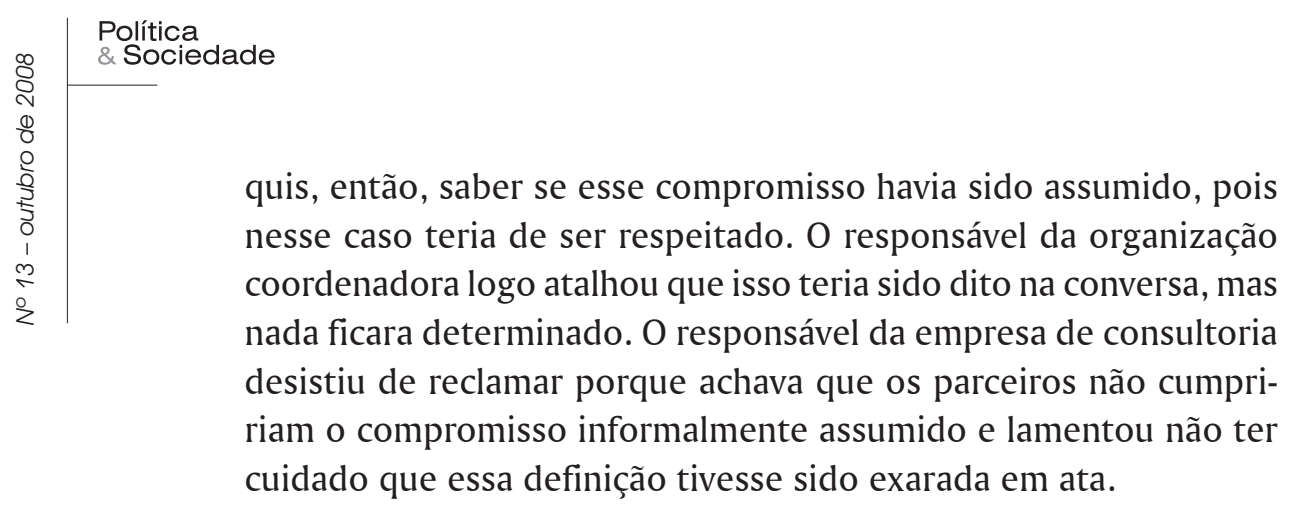

\subsubsection{Confrontação e aliança}

O responsável de uma organização, achando o seu orçamento inferior aos seus custos operacionais, resolveu requerer reforço do seu orçamento junto da Direção do Programa, alegando a complexidade do Balanço de Competências, de que era responsável, exigia elevada ocupação de recursos técnicos que nela tinha de aplicar. Esta incapacidade tinha sido numa outra reunião denunciada pelo responsável da empresa de consultoria, o que causou declarado desagrado entre os membros daquela organização e recíproca imputação negativista de responsabilidades. Agora, foi o primeiro a declarar o seu apoio àquela pretensão por considerar que era condição necessária à boa execução da atividade. Por sua vez, para reforçar o seu orçamento, a empresa de consultoria propôs à PD a criação de novo RTP - avaliação da satisfação dos clientes das organizações da economia social - justificando a sua necessidade com a complexidade da metodologia e a falta de preparação técnica das organizações para realizar, pela importância dos seus resultados, para a melhoria contínua da qualidade e o risco de limitada isenção na coleta dos dados e análise dos resultados se feita pelas organizações parceiras. A sua proposta não foi aprovada pela PD, alegando os seus membros que já havia muito trabalho para realizar, mas o responsável daquela organização foi igualmente o primeiro a declarar o seu apoio à proposta.

\subsection{Princípios da coreografização}

A dança é temporalização do corpo nos seus movimentos, integrando a coexistência e a complexidade de seus ritmos, re- 
criados por involução descontínua que o leva a sucessivos seres e devires, nos novos gestos que compõem novas imagens, tornando a coreografia arte que liga o pessoal e o impessoal, o atual e o virtual (MOEHLECK \& FONSECA, 2005). A dança é diálogo físico, espécie de discurso composto de ícones e índices que podem receber diversos significados, mas que partilham o mesmo estilo cultural (LEWIS, 1992). A dança é interação social nos cenários dos encontros e pode mesmo ser o próprio encontro, quando dançantes e platéias partilham a coreografia e atualizam sequiências de figuras em aspiração. A dança é previsão e improviso, sequiência e antecipação, realidade e ilusão. Mas, na gestão de projetos em parceria, os seus movimentos parecem seguir princípios coreográficos, modos de combinar os movimentos:

Quanto mais alargada a participação e escassos os recursos, mais necessária a legitimação formal dos acordos.

A partilha de recursos sempre pode levantar problemas nas parcerias - quando são escassos ou quando sobram. Os recursos nunca são infinitos devido ao seu consumo, desperdício ou degradação. Neste caso, também houve desperdícios, pois foram realizadas atividades de modo deficitário ou que permitiram atingir fins pretendidos que não justificavam os recursos afetos. Algumas delas, insuficientemente realizadas, permitiram libertar recursos financeiros que ficaram disponíveis para outras aplicações. Quando foi necessário decidir sobre o destino a dar ao dinheiro disponível, o critério que determinou a sua apropriação foi o da máxima conveniência partilhada e esta era o financiamento da certificação a realizar por entidade externa e acreditada pelo Instituto Português da Qualidade. Nestes casos, acordos tácitos ou não formais podem ser facilmente ignorados, por deliberada ou involuntária omissão, e a memória oral, própria de grupos informais ou íntimos, perde valor só sendo reconhecido valor à memória escrita. Nas interações quotidianas, os membros da parceria podem desenvolver regimes de relação informal e mesmo íntimo, mas quando se trata de distribuir recursos a relação torna-se circunstancialmente mais impessoal para se impor a vontade do grupo maior e só a impessoalidade do registro escrito pode limitar o seu poder decisório. 
Quanto mais equilibrada a legitimidade, mais significativa a razão técnica.

As parcerias são montadas para colher benefícios comuns, seja de natureza material ou simbólica. Elas são particularmente vantajosas quando se verifica escassez de recursos e existe predisposição organizacional para partilhar regras e recursos e adotar modos concertados de atuar. Muitas vezes, são as diferenças de opinião política e as incompatibilidades de caráter que inibem ou dificultam a construção de parcerias. Neste caso, havia dois fatores inibidores - o receio de que a verba que se pudesse captar não fosse suficiente para todas as organizações interessadas e o receio da ineficácia da cooperação devida a incompatibilidade de caracteres de alguns dos seus membros. Mediante o confronto de dois grupos, presumidamente detentores de iguais direitos de integrar a parceria, reconhecidas pela câmara municipal, entidade mais política e agregadora, a conveniência do critério de decisão deslocou-se para o domínio técnico. A adoção deste critério permite encontrar solução presumidamente mais isenta e retirar o indesejável peso que os sentimentos de vitória e derrota acarretam.

Quanto mais controlada a competência normativa, maior a dominação.

A empresa de consultoria participa na PD para emprestarlhe o conhecimento da norma de referência e a competência para adaptá-la ao setor social. No início do projeto era a única entidade capaz de fazer essa transposição e montar o SGQ e, ainda, ajudar noutras decisões relativas à gestão de recursos humanos. Contudo, o projeto consiste na transferência e desenvolvimento desses conhecimentos e competências nas restantes organizações parceiras, beneficiárias direta do desenvolvimento organizacional almejado. Assim, o decorrer do tempo permite ou promove a alteração da relação de dependência, sendo imperativo que a empresa qualifique os quadros técnicos das organizações e, ao fazê-lo, aliene a principal base do seu poder. Trata-se de inevitável efeito, desejável para os parceiros e indesejável para a empresa. O poder desta de influenciar os processos de decisão é progressivamente menor e, quando se têm de tomar decisões importantes no final do projeto, as possibilidades de ver realizados os seus interesses são menores. Nesta altura, a 
partilha de interesses comuns dos parceiros pode impor-se a outros critérios, mesmo se tocados por varinha da moral.

\section{Análise metafórica do desenvolvimento organizacional}

As metáforas estão associadas a modos de pensar e a formas de ver, permitindo olhar a organização de modo específico e incompleto, diagnosticar e melhorar os seus processos e desempenho (MORGAN, 1995, p.16). O seu uso permite diversas vantagens: interpretar mais facilmente a realidade organizacional, favorecendo mais a atribuição de sentido, por implicação e conotação, do que a simples linguagem literal (KNOWLES \& MOON, 2005, p.11-12); são veículos linguiísticos transportadores de possibilidades de construção da realidade, importantes meios de criatividade na percepção e na ação (KRIPPENDORFF, 1993); articula a vida experienciada e a vida em curso e, por isso, faz parte das nossas vidas e do modo como pensamos e falamos, facilitando a conceitualização e a comunicação (LAKOFF \& JOHNSON, 1980, p.3-6). Quando adotamos as metáforas da dor-dança-drama, adotamos um modo de ver o desenvolvimento organizacional e de perspectivar a atuação das pessoas e sujeitamos a nossa visão às possibilidades hermenêuticas da metáfora adotada, beneficiando e padecendo dos instrumentos interpretativos que nos faculta.

Neste caso, a análise permitida por esta alegoria permite analisar como o desenvolvimento organizacional foi decidido em processos de decisão partilhados e coletivos que estimularam a mudança de comportamento organizacional e contribuíram para a evolução da configuração social dentro de cada organização, dentro da economia nacional e dentro da economia global. Situei esta análise na teoria sociológica histórica de Elias (2006) para realçar alguns aspectos da sua teoria: a importância da evolução social ritmada pela evolução das configurações; as interdependências estruturais de pessoas mutuamente orientadas e dependentes que criam padrões mutáveis de interdependências (ELIAS, sd, p. 161).

Contudo, ao não adotar a metáfora do jogo, reduzo as possibilidades de explicar a evolução das configurações pela perspectiva 
política, pelas tensões e conflitos estruturados e estruturais entre grupos que perdem e adquirem funções (idem, p. 191). Esta opção não se deve à arriscada aceitação de que a teoria da evolução das configurações não ajudaria a compreender as mudanças que a certificação de SGQ implica no desenvolvimento das organizações. De resto, as implicações nas relações entre os grupos são previstas, desejadas e até evidentes: valorização das expectativas e necessidades dos clientes na gestão quotidiana, reforço do poder dos gestores face aos diretores, reforço da capacidade competitiva e de sobrevivência das organizações certificadas face às não certificadas, melhoria da capacidade de negociação das IPSS face ao governo, aumento da competitividade nacional face às nações concorrentes na economia global.

Preferi adotar metáforas que permitissem mais facilmente observar as pessoas em interação para aproveitar a oportunidade aberta pela observação participante realizada. A metáfora da dor permitiu ver alterações na orientação da conduta como reflexo da dinâmica sentimental motivada nas interações volitivas entre participantes ambiguamente movidos entre constrangimentos dos interesses cooperativos e imperativos dos interesses privativos. A metáfora da dança permitiu ver os movimentos dos participantes, orientados para alinhamentos variáveis, trocando de parceiros quando a troca revelava-se vantajosa e desenhando e evoluindo em sucessivas figuras promotoras de novas alianças discursivas e pragmáticas. A metáfora do drama permitiu ver a compatibilidade e conflitualidade de papéis sociais representados, a convivência entre utilidade e legitimidade, a continuidade entre representação da realidade e realidade assumida. A mudança organizacional bem sucedida e feita de tudo isto.

\section{Referências}

AXELROD, R. The complexity of Cooperation. New Jersey: Princeton University, 1997.

ELIAS, N. Introdução à Sociologia. Lisboa: 70, sd. 
. O processo civilizacional. Lisboa: D. Quixote, 2006.

GIDDENS, A. Central Problems in social Theory: Action, Structure and contradiction in social Analysis. London: McMillan, 1979.

Hutchinson, 1988.

. New Rules of sociological Method, London:

GOFFMAN, E. A representação do eu na vida cotidiana. Petrópolis: Vozes, 1983.

GOLEMAN, D. Emotional Intelligence: why it can matter more than IQ. London: Bloomsbury, 1996.

HUNTER, M. Making Peace with chronic Pain. New York: Brunner/ Mazel, 1996.

KANNER, R. Definitions. In.: . (org.). Pain measurement

Secrets. Philadelphia: Hanley \& Belfus, 1997.

KNOWLES, M. \& MOON, R. Introducing metaphor. New York: Routledge, 2005.

KRIPPENDORFF, K. Major Metaphors of Communication and some Constructivist Reflections on their Use. Cybernetics \& Human Knowing, London, v. 2, n. 1, p. 3-25, 1993.

LAKOFF, G. \& JOHNSON, M. Metaphors we live by. Chicago and London: University of Chicago, 1980.

LAKOFF, G. The contemporary theory of metaphor. In.: ORTONY, A. (ed.) Metaphor and thought. Cambridge: Cambridge University. 1996.

LEWIS, J. Ring of liberation: deceptive discourse in Brazilian Capoeira. Chicago: Chicago, 1992.

MOEHLECKE, V. \& FONSECA, T. Da dança e do devir: o corpo no regime do sutil. Revista do Departamento de Psicologia, Niterói, v. 17, n. 1, p. 45-59, jan-jun, 2005.

MORGAN, G. Imagens da organização. Rio: J. Zahar, 2006.

PAYNE, S. \& HORN, S. Pain: Theory, Research and Intervention. Buckingham, Philadelphia: Open University, 1997. 
